\title{
DAC-Liste der Hilfeempfängerländer, 1997
}

\section{(2) OpenEdition \\ 1 Journals}

Electronic version

URL: http://journals.openedition.org/sjep/810

DOI: 10.4000/sjep.810

ISSN: 1663-9677

Publisher

Institut de hautes études internationales et du développement

\section{Printed version}

Date of publication: 1 janvier 1999

Number of pages: $271-272$

ISSN: 1660-5926

\section{Electronic reference}

« DAC-Liste der Hilfeempfängerländer, 1997 », Schweizerisches Jahrbuch für Entwicklungspolitik [Online], 18 | 1999, Online erschienen am: 27 August 2012, abgerufen am 08 September 2020. URL : http:// journals.openedition.org/sjep/810 ; DOI : https://doi.org/10.4000/sjep.810 


\section{TEIL: ENTWICKLUNGSLÄNDER UND -GEBIETE (ÖFFENTLICHE ENTWICKLUNGSHILFE)}

\section{Am wenigsten entwickelte Länder (LDC)}

$\begin{array}{lll}\text { Afghanistan } & \text { Kambodscha } & \text { Niger } \\ \text { Angola } & \text { Kap Verde } & \text { Ruanda } \\ \text { Äquatorialguinea } & \text { Kiribati } & \text { Salomon-Inseln } \\ \text { Äthiopien } & \text { Komoren } & \text { Sambia } \\ \text { Bangladesch } & \text { Kongo, Demokratische Rep. } & \text { São Tomé und Príncipe } \\ \text { Benin } & \text { Laos } & \text { Sierra Leone } \\ \text { Bhutan } & \text { Lesotho } & \text { Somalia } \\ \text { Burkina Faso } & \text { Liberia } & \text { Sudan } \\ \text { Burundi } & \text { Madagaskar } & \text { Tansania } \\ \text { Dschibuti } & \text { Malawi } & \text { Togo } \\ \text { Eritrea } & \text { Malediven } & \text { Tschad } \\ \text { Gambia } & \text { Mali } & \text { Tuvalu } \\ \text { Guinea } & \text { Mauretanien } & \text { Uganda } \\ \text { Guinea-Bissau } & \text { Mosambik } & \text { Vanuatu } \\ \text { Haiti } & \text { Myanmar } & \text { Westsamoa } \\ \text { Jemen } & \text { Nepal } & \text { Zentralafrikanische Rep. }\end{array}$

Sonstige einkommensschwache Länder (BSP pro Einwohner unter 765 Dollar 1995)

$\begin{array}{lll}{ }^{*} \text { Albanien } & \text { Guyana } & \text { Nicaragua } \\ { }^{*} \text { Armenien } & \text { Honduras } & \text { Nigeria } \\ { }^{*} \text { Aserbaidschan } & \text { Indien } & \text { Pakistan } \\ \text { Bosnien-Herzegowina } & \text { Kamerun } & \text { Senegal } \\ \text { China } & \text { Kenia } & \text { Simbabwe } \\ \text { Elfenbeinküste } & { }^{*} \text { Kirgistan } & \text { Sri Lanka } \\ { }^{*} \text { Georgien } & \text { Kongo, Demokratische Rep. } & \text { *Tadschikistan } \\ \text { Ghana } & \text { Mongolei } & \text { Vietnam }\end{array}$

Länder mit mittlerem Einkommen (untere Einkommensstufe) (BSP pro Einwohner 766-3035 Dollar 1995)

Ägypten

Algerien

Belize

Bolivien

Botswana

Costa Rica

Dominikanische Republik

Dominica

Ecuador

El Salvador

Fidschi

Gebiete unter

palästinensischer Verwaltung

Grenada

Guatemala

Indonesien

Irak

Iran
Jamaika

Jordanien

Jugoslawien, Bundesrep.

*Kasachstan

Kolumbien

Korea, Demokratische Rep.

Kuba

Libanon

Marokko

Marshall-Inseln

Mazedonien

(ehemalige Jugoslawische Rep.) Tonga

Mikronesien

*Moldawien'

Namibia

Niue

Palagos-Inseln

Panama
Papua-Neuguinea

Paraguay

Peru

Philippinen

St. Vincent und Grenadinen

Surinam

Swasiland

Syrien

Thailand

+ Timor

+ Tokelau

Tunesien

Türkei

*Turkmenistan

*Usbekistan

Venezuela

+Wallis und Futuna

* Mittel- und osteuropäische Länder(MOEL)/Gemeinschaft Unabhängiger Staaten (GUS)

1. Moldawien wurde ab 1. Januar 1997 in den 1. Teil umgestuft. Bis 1996 ist die Hilfe für Moldawien in der öffentlichen Hilfe für die MEOL/GUS enthalten.

+ Gebiete 


$\begin{array}{lcc}\text { Länder mit mittlerem Einkommen (obere Einkommensstufe) (BSP pro } & \text { Einwohner 3036-9385 Dollar 1995) } \\ \text { +Anguilla } & \text { Kroatien } & \text { +St. Helena } \\ \text { Antigua und Barbuda } & \text { Libyen' } & \text { St. Kitts und Nevis } \\ \text { Saudi-Arabien } & \text { Malaysia } & \text { St. Lucia } \\ \text { Argentinien } & \text { Malta } & \text { Seychellen } \\ \text { Bahrain } & \text { Mauritius } & \text { Slowenien } \\ \text { Barbados } & \text { +Mayotte } & \text { Südafrika } \\ \text { Brasilien } & \text { Mexiko } & \text { Trinidad und Tobago } \\ \text { Chile } & + \text { Montserrat } & + \text { Turks-und Caicos-Inseln } \\ \text { Cook-Inseln } & \text { Nauru } & \text { Uruguay } \\ \text { Gabun } & \text { Oman } & \end{array}$

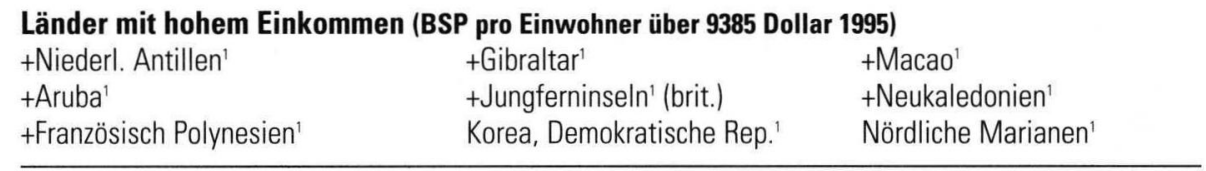

\section{TEIL: TRANSITIONSLÄNDER UND -GEBIETE (ÖFFENTLICHE HILFE)}

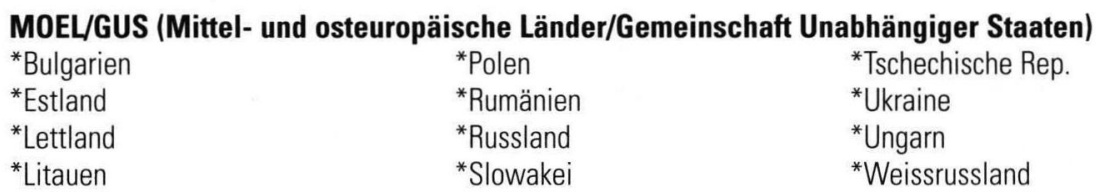

\section{Fortgeschrittenere Entwicklungsländer und -gebiete ${ }^{2}$}

$\begin{array}{lll}\text { Bahamas } & \text { Chinesisch Taipeh } & \text { Katar } \\ \text { +Bermuda-Inseln } & + \text { Falkland-Inseln } & \text { Kuweit } \\ \text { Brunei } & \text { Hongkong, China } & \text { Singapur } \\ \text { +Cayman-Inseln } & \text { Israel } & \text { Vereinigte Arabische Emirate } \\ & & \text { Zypern }\end{array}$

Anmerkung: Gemäss der vom DAC 1993 beschlossenen Politik setzt sich die DAC-Liste der Hilfeempfängerländer aus zwei Teilen zusammen. Die periodischen Überprüfungen nach festgesetzten Kriterien können dazu führen, dass bestimmte Empfängerländer von einem Teil in den anderen, besonders vom 1. in den 2. Teil verlegt werden (vgl. den Bericht "Coopération pour le développement", 1996, p.A101).

Die Statistiken in diesem Bericht umfassen die letzten Daten für das Jahr 1996 und geben somit die DAC-Liste wieder, wie sie 1996 war. Die oben aufgeführte Liste tritt ab 1. Januar 1997 in Kraft. Die vorausgehenden Anmerkungen erklären unter anderem die Unterschiede zwischen den Listen für 1996 und für 1997.

Quelle: DAC-Bericht 1997, OECD.

Anmerkung des Redaktionskomitee:

Die Ländereinstufung beruht auf der Klassifikation des OECD-Entwicklungshilfeausschusses (DAC).

1. All diese Länder und Gebiete sollen ab 1. Januar 2000 unter die fortgeschrittensten Länder eingestuft werden, wenn nicht eine Ausnahme beschlossen wird.

2. Die in Kursivschrift angegebenen Empfängerländer waren bis Ende $1996 \mathrm{im}$ 1. Teil der DAC-Liste aufgeführt. Bis 1996 ist die Hilfe für diese Länder in der öffentlichen Entwicklungshilfe für Länder mit hohem Einkommen enthalten. Sie wurden am 1. Januar 1997 in den 2. Teil umgestuft. Die anderen Empfängerländer in dieser Tabelle wurden ab 1. Januar 1996 in den 2. Teil umgestuft. Bis 1995 ist die Hilfe für diese Länder in der öffentlichen Entwicklungshilfe für Länder mit hohem Einkommen enthalten.

+ Gebiete.

* Mittel- und osteuropäische Länder (MOEL)/Gemeinschaft Unabhängiger Staaten (GUS). 